\title{
Effect of Moisture Content on Mechanical Properties of AAM Natural Fiber-Reinforced Isophthalic Polyester Composites
}

\author{
T. Ramakrishnan $\mathbb{D}^{1},{ }^{1}$ S. Senthil Kumar $\mathbb{D}^{2},{ }^{2}$ Samson Jerold Samuel Chelladurai $\mathbb{D}^{3}{ }^{3}$ \\ S. Gnanasekaran $\mathbb{D}^{4}{ }^{4}$ N. K. Geetha $\mathbb{D}^{5},{ }^{5}$ Ramesh Arthanari $\mathbb{D}^{6},{ }^{6}$ and Baru Debtera $\mathbb{D}^{7}$ \\ ${ }^{1}$ Department of Mechanical Engineering, Sri Eshwar College of Engineering, Coimbatore, Tamilnadu, India \\ ${ }^{2}$ Department of Mechanical Engineering, RMK College of Engineering and Technology, Puduvoyal 601206, India \\ ${ }^{3}$ Department of Mechanical Engineering, Sri Krishna College of Engineering and Technology, Coimbatore, Tamilnadu, India \\ ${ }^{4}$ Department of Mechanical Engineering, Sri Shakthi Institute of Engineering and Technology, Chinniyampalayam, Coimbatore, \\ Tamil Nadu, India \\ ${ }^{5}$ Department of Mathematics, Dayananda Sagar College of Engineering, Bangalore 560078, India \\ ${ }^{6}$ Department of Mechanical Engineering, Chennai Institute of Technology, Chennai, Tamil Nadu, India \\ ${ }^{7}$ Department of Chemical Engineering, College of Biological and Chemical Engineering, \\ Addis Ababa Science and Technology University, Addis Ababa, Ethiopia
}

\begin{abstract}
Correspondence should be addressed to T. Ramakrishnan; ramakrishnankct@gmail.com and Baru Debtera; baru.debtera@aastu.edu.et
\end{abstract}

Received 26 October 2021; Revised 16 December 2021; Accepted 5 January 2022; Published 28 January 2022

Academic Editor: Ravichandran M

Copyright (c) 2022 T. Ramakrishnan et al. This is an open access article distributed under the Creative Commons Attribution License, which permits unrestricted use, distribution, and reproduction in any medium, provided the original work is properly cited.

Composite fiber reinforcement is one such proficient material that substitutes for useful applications for conventional and polyester blends where little weight and thus less energy conservation is required. This study highlighted the importance of recently discovered Agave Angustifolia marginated (AAM) fibers extracted by a manual process from AAM plants. This paper observes the various properties of the mechanical and moisture intake characteristics of AAM fiber and compares these to other naturally occurring fibers. Using isophthalic polyester resin, the mixed chopped AAM fiber-reinforced composite is prepared and detailed preparation techniques are presented. During physical composite testing, fiber pull-outs on the broken samples were investigated. Additionally, the experimental evidence demonstrates that increasing the volume fraction helps to increase the tensile, bending, and modulus of the AAM fiber composite. The chopped fiber isophthalic polyester reinforcement reaches its improved tensile strength and modulus at a $25 \% \mathrm{Vf}$ about the $20 \mathrm{~mm}$ length of the fiber.

\section{Introduction}

The global economy is rapidly progressing through the process of energy conservation and reduction. Typically, natural fibers are used to reduce the weight of components; i.e., the fibers are strengthened with the appropriate matrix. Natural plant fibers offer numerous benefits over synthetic fibers in terms of cost, sustainability, renewable resources, and biodegradability. In the field of natural fibers, several authors have conducted their investigations. Natural plant fibers have numerous advantages over synthetic fibers in terms of cost, sustainability, renewable, and biodegradability. In the field of natural fibers, several authors have conducted their investigations into the topic [1]. Natural fibers are typically used in order to decrease the components' weight and increase their strength. The ASTM standards explored the relationship between filler loading ( 3 to $12 \%$ by weight) and the mechanical and physical properties of hybrid composite materials. The tensile strength of the polymeric material was found to be $34 \%$ higher than polyester, and the impact strength was determined to be 3.87 significantly greater [2]. These include tensile, compressive, and impact strength as well as tribological properties. Interfacial bonding is the main determinant of mechanical and tribological properties. Plant fiber thermoset composites' wear and friction 
characteristics can be regulated by fillers and reinforcement orientation [3]. The innovation propels have prompted the present another age of specialized and keen materials. These new high-esteem materials can be created by surface treatment, synthetic uniting, 3D design, and nanotechnologies [4]. Advances in nanotechnology have permitted the plan of new materials with explicit properties since they offer the likelihood to control their morphological attributes [5]. The interfacial attachment was observed to be an overwhelming component regarding mechanical and tribological properties [6]. Wear and frictional attributes of plant fiber-based thermoset composites can be controlled utilizing appropriate fillers and support direction. A conversation on interfacial attachment and its impact on composite execution have likewise been incorporated $[7,8]$. Because the present technology cannot reduce the weight of materials, increase spans, or build thin constructions, the search for new composite materials is sparked. Polymerbased reinforcement with fibers (FRP) has a high strengthto-weight ratio while being less weight when the use of FRP encourages civil engineers to reinforce and repair deteriorated RC structures $[9,10]$. For variable boundary conditions, geometric parameters, and material qualities, the theory is used to quantify the impacts of axial distributed load/terminal force and temperature fluctuation on free vibration and buckling. At a very low computing cost, the current theory can accurately estimate the natural frequencies and buckling capabilities of multilayered beams [11-18]. The composite's mechanical characteristics are scrutinized for quality and durability. With the inclusion of nanoclay, the mechanical characteristics of the coir fiber epoxy composite were significantly improved at a reduced cost, making it an attractive alternative to glass fibers for several applications [19-53].

\section{Materials and Experimental Methods}

2.1. Fiber Materials. A width range of $30 \mathrm{~cm}$ to $150 \mathrm{~cm}$ is observed among the AAM plants cultivated throughout the field. The AAM leaf and the sand are washed with acetone before plucking. The leaves' green exteriors (stamps) are carefully removed. To remove the plant's secondary and tertiary walls, the plants are immersed in water for four days. Afterward, they are used in a biodegradable platform that allows the fibers to be harvested continuously. The unpasteurized AAM is then chopped into many thicknesses, such as $05 \mathrm{~mm}, 50 \mathrm{~mm}, 80 \mathrm{~mm}, 110 \mathrm{~mm}$, and $140 \mathrm{~mm}$, for polymer sample preparation.

2.2. Synthetic Polyester Resin. The study employed an isophthalic monosaturated polyester resin. To cure the resin, both the accelerator, Ketone Peroxide and Methyl Ethyl, and the catalyst, Cobalt Naphthalene, are used in combination [15]. When compared to other resins, thermoset polyester resin is one of the most cost-effective choices owing to its extremely low water absorption capacity, better mechanical strength, and outstanding bonding ability, among other properties. To enhance the bonding strength $2: 1$ mix ratio of resin-hardener by volume used, the isophthalic polyester resin exhibits a number of unique characteristics, which are listed in Table 1.

\subsection{Polyester Resin Reinforced Composite Materials Sample} Preparation. The AAM fibers are obtained from the water after four days, after which their moisture content is removed by placing the fibers in inhaled sunlight for eight hours. After they have been heated to $120^{\circ} \mathrm{C}$ for 60 minutes, the fibers are transferred to the hot air oven. To make the composites, the fibers are first sliced. A simple hand lay-up method provided composite specimens with volume concentrations of $10 \mathrm{wt} . \%$, 15wt.\%, 20wt.\%, 25wt.\%, and 30wt.\%. To cure isophthalic polyester resin, $1 \%$ catalyst and $1 \%$ accelerator have been used. Composite specimens are made with preparation steel dies. The releasing agent is first applied to the male and female die sections to help remove the samples after phase transformation. Fibers are then spread across the die, and the surfaces are left to dry for 15 minutes.

In order to maintain the total fiber orientation and homogeneity, steel roller rolls are used to roll the composite into the isotypic properties of the material so that most of the air bubbles are removed. The closed mold is held on the hydraulic press for 8 hours, under compressive pressure, while curing. To prepare the desired composite plate, the resin is injected to reinforce these same fibers to a total of 4 millimeters. Once the composite plate has been postcured for one hour in an oven, it is ready for use.

\subsection{Examination of the Fiber and Composites}

2.4.1. Single Fiber Tensile Testing. To determine the tensile properties of an unremitting AAM fiber over a long length, an ASTM D3379-75 appropriate testing method that used the Instron Universal Testing machine was used as per the ASTM D3379-75 standard. Each fiber's gauge length was set to $100 \mathrm{~mm}$, and a 1000-gram load cell was carried out to perform the test at various levels. The grippers' speed was set to $5 \mathrm{~mm} /$ min, and this acceleration was maintained all through the testing. In this study, twenty-five tests were performed, In this experimental study, the failure/break, tensile modulus, and tensile strength average values were obtained [16].

2.4.2. Tensile Strength of the PRC Materials. An electronic tensometer was used to test the composite specimen's tensile properties. The dog bones samples were made to ASTM D 638 standards. At the gauge length of $50 \mathrm{~mm}$, the samples remained machine-cut to a fixed size of $165 \mathrm{~mm}, 13 \mathrm{~mm}$, and $4 \mathrm{~mm}$. The tensometer utilized a load cell with a capacity of $5 \mathrm{kN}$ to test for this. In order to track which specimen goes with which number, five identical test samples (S1, S2, S3, S4, and S5) were used for each test. The composites' tensile strength, tensile load, elongation at break, and elastic modulus were all measured in this experiment [17].

2.4.3. Flexural Strength of the PRC Composite. The springmass testing machine was also used to conduct three-point flexural testing in accordance with ASTM D 790 standards. 
TABle 1: Effects of the isophthalic Synthetic Polyester Resin.

\begin{tabular}{lccc}
\hline S. No & Properties & Unit & Range \\
\hline 1 & Density & $\mathrm{kg} / \mathrm{m}^{3}$ & 1125 \\
2 & Flexural strength & $\mathrm{MPa}$ & 30 \\
3 & Flexural modulus & $\mathrm{GPa}$ & $1.2-1.5$ \\
4 & Shrinkage & $\%$ & $0.004-0.008$ \\
5 & Tensile modulus & $\mathrm{GPa}$ & $0.8-1.1$ \\
6 & Compressive strength & $\mathrm{MPa}$ & $90-250$ \\
7 & Tensile strength & $\mathrm{MPa}$ & 18 \\
8 & Specific gravity & - & $1.1-1.46$ \\
\hline
\end{tabular}

The samples were cut to $125 \mathrm{~mm}, 12 \mathrm{~mm}$, and $4 \mathrm{~mm}$ in size. The samples were tested and the span to depth ratio was determined to be $16: 1$. A $6 \mathrm{kN}$ load cell was employed in this experiment, with a speed (crosshead) of $2.5 \mathrm{~mm} / \mathrm{min}$. Five equal test specimens were made for each flexural test and labeled F1, F2, F3, F4, and F5. The displacement of the samples was measured using a computerized dial gauge, and the composites' flexural parameters such as strength properties, modulus of elasticity, flexural load, and displacement at breaks were analyzed. Five equal samples were broken between the gauge length and the tensile testing during the experiment [18].

2.4.4. Moisture Absorption Test Procedure. According to ASTM standards, flexural and tensile specimens were to be cut from the fabricated plate. In order to absorb the moisture, the surfaces of the test samples were bonded using polyester resin and placed in a warm atmosphere. The first specimens were dried in an air oven at $60^{\circ} \mathrm{C}$. After conditioning the PRC specimens, they were immersed in distilled water at $30^{\circ} \mathrm{C}$ for about five days. The samples were gradually separated from the water and dried using filtrate to eliminate excess moisture from the surface, before being quantified using a weighing scale with a range of $0.01 \mathrm{mg}$. Once saturation limit was reached, the samples were placed in water so that sorption could continue until absorption was complete. To avoid evaporation errors, the measurement was finished in thirty seconds. We used ASTM D570 for 5 days, the sample had been measured, and the process is repeated.

\section{Results and Discussion}

3.1. Mechanical Characteristics of the AAM Fiber. The raw single AAM fibers are intricate for tensile testing with an appropriate gauge span of $100 \mathrm{~mm}$. The twenty-five samples were used to determine the fiber tensile properties based on the average value of load and area. Table 2 compares tensile strength values of AAM fiber to those of other available natural fibers. The fiber diameter was varied from $493 \mathrm{~mm}$ to $500 \mathrm{~mm}$. Density is an important parameter to consider when designing lightweight materials. The density of the AAM fiber was clearly lower than that of the other natural fibers in the table. However, it was slightly more than that of spatha rachilla, rachis fibers, elephant grass, and petiole bark. AAM fiber had a higher average tensile strength than other natural fibers such as petiole bark, spatha rachilla, rachis fibers elephant grass, kenaf, root, and coir fibers. The maximum load at break was somewhat greater than that of many other natural fibers. On the basis of the available qualities, it is obvious that the AAM fiber is a viable alternative to natural fibers in the future.

The percentage elongation at break was slightly higher than that of elephant grass, petiole bark, pineapple leaf, date, and bamboo, but it was the same as that of flex, banana, hemp, and jute. Based on the available properties, it is clear that the AAM fiber is one of the future natural fiber alternatives $[18,19]$.

\subsection{Effect of Tensile Behavior of AAM-PRC Materials.} Compared to different fiber volume fractions, the tensile characteristics of sliced AAM-PRC materials are anticipated to be identical to those of fibers with varying volume concentration and lengths. As illustrated in Figure 1, the material's strength fluctuates with the difference in fibers volume concentration as the various fiber lengths are altered. If the length of the fiber is increased from 5 to $140 \mathrm{~mm}$, the tensile strength typically decreases from 19.15 to $16.25 \mathrm{MPa}$. Very little fiber accumulation is found in the composite, resulting in a $15.8 \%$ increase in the present case between both the higher and lower tensile strengths.

A similar linear drop in tensile strength can be seen up to $25 \%$. The tensile strength increases by $15 \%$ between both the maximum and minimum are $10.85 \%$. Due to the more accumulation of fiber in the composite, the Vf has been reduced by 10 percent. As well, the amount of efficiency was further reduced to 09.33 percent for $20 \% \mathrm{Vf}$. Tensile forces are exerted at a fiber length of $20 \mathrm{~mm}$ in the current project, and it is calculated for a proportionate volume concentration of $25 \%$. The $25 \% \mathrm{Vf}$ tensile strength improvement percentage is $11.49 \%$. Compared to the previous figure of $20 \%$, the new percentage is higher. Since the accumulation of fibers in the composite is more than in the composition, the fibers in the composite have more fibers with higher fiber ends than the $140 \mathrm{~mm}$ in the composition.

The tensile strength of a fiber is significantly influenced by the ends of the fiber. When the percentage volume fraction reaches 30 , the tensile strength of the material drops rapidly to $13.02-9.85 \mathrm{MPa}$ for a variety of fiber lengths as illustrated in Figure 2. The results show that there is substantially less stress and pressure on the fiber because of the lower volume content in the matrix of composites. The composite's tensile strength, as determined by fiber length, ranges between 20 and $50 \mathrm{~mm}$. For $20 \mathrm{~mm}$ and $50 \mathrm{~mm}$ fiber lengths, there was a $39.99 \%$ improvement from $10 \% \mathrm{Vf}$ to $25 \%$ Vf. The composite's tensile strength rises as the fiber content rises. In order to experience a good load transfer, you must see the fibers and the matrix separate from each other. Increased fiber length and volume fraction reduce tensile strength.

\subsection{Flexural Properties of AAM Fiber-Reinforced Composites.} The flexural property is a significant parameter in a composite material that is particularly helpful in structural applications. Figure 3 depicts the variance in flexural strength 
TABLE 2: Difference between the tensile behavior of AAM fiber with numerous natural fibers.

\begin{tabular}{|c|c|c|c|c|c|}
\hline Fiber name & Density $\left(\mathrm{kg} / \mathrm{m}^{3}\right)$ & Diameter (um) & Tensile strength (MPa) & Tensile modulus (GPa) & $\%$ Elongation \\
\hline Cotton & 1600 & - & $287-597$ & $5.5-12.6$ & $3-10$ \\
\hline Ramie & 1500 & & $220-938$ & $44-128$ & $2-3$ \\
\hline Flax & 1500 & - & $345-$ & $27.6-80$ & $1.2-3.2$ \\
\hline Hemp & 1480 & - & $550-900$ & 70 & 1.6 \\
\hline Jute & 1460 & - & $393-800$ & $10-30$ & $1.5-1.8$ \\
\hline Sisal & 1450 & $50-300$ & $227-400$ & $9-20$ & $2-14$ \\
\hline Pineapple & 1440 & $20-80$ & 413 & $34.5-$ & $0.8-1$ \\
\hline Leaf & & & 1627 & 82.5 & \\
\hline Kenaf & 1400 & 81 & 250 & 4.3 & - \\
\hline AAM fibers & 1608 & $49.3-500$ & 512 & 38.71 & 1.6 \\
\hline
\end{tabular}

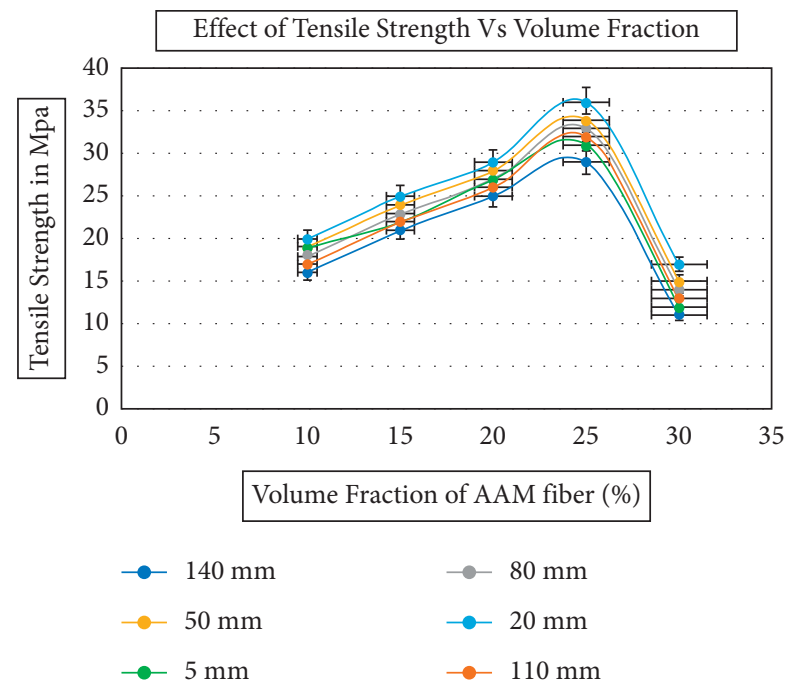

FIGURE 1: Effect of Tensile strength versus volume fraction of AAM fiber through different fiber lengths.

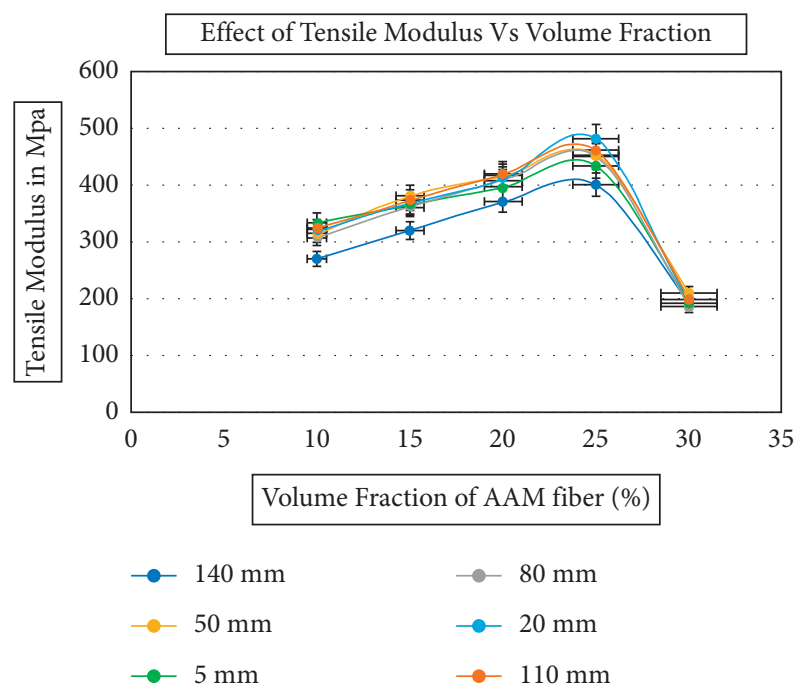

Figure 2: Effect of tensile modulus versus volume fraction of AAM fibers of various lengths.

values as the volume fractions increase by a percentage. It is discovered that the flexural values eventually increase close to $20 \% \mathrm{Vf}$. The flexural strength of a composite increases

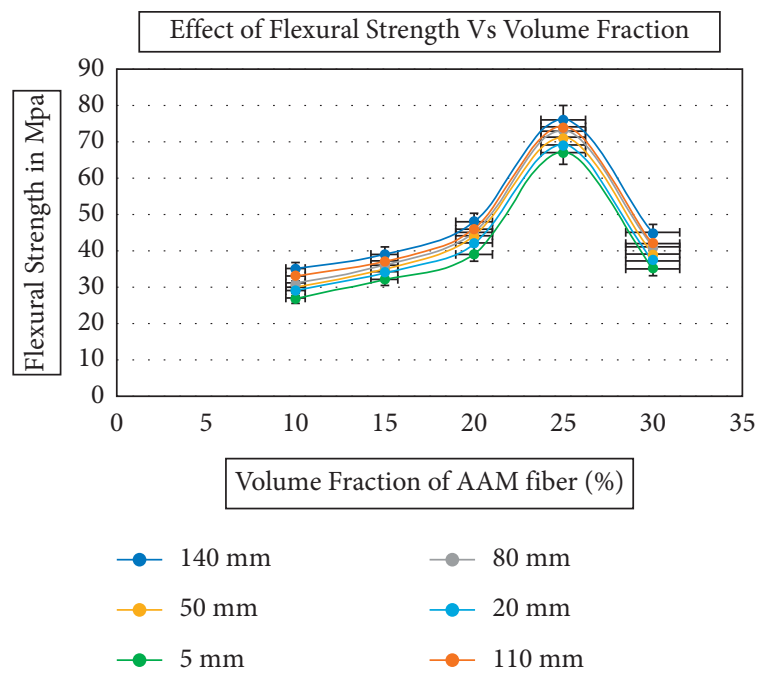

Figure 3: The relationship between flexural strength and the volume fraction of AAM fiber is explored through the use of different fiber lengths.

dramatically once the Vf of the fiber exceeds $20 \%$. When the $\mathrm{Vf}$ of fiber in the composite is $30 \%$, the increasing trend abruptly reverses and the flexural strength is drastically reduced. If the fiber content is greater than $30 \% \mathrm{Vf}$ during matrix composites, it results in minimal filling of the matrix into the encircling fibers. A $10 \% \mathrm{Vf}$ composite has a flexural strength of $32.45 \mathrm{MPa}$. In addition, the variation of fiber concentration and the flexural strength increases by $11.01 \%$.

By increasing the fiber content of the composite by $15 \%$, the maximum flexural strength increases to $37.14 \mathrm{MPa}$, and the flexural strength varies widely by 5.87 percent depending on the fiber content of the composite. The increase in flexural strength value persists, as in prior situations, up to a maximum of 25 percent Vf. The length of fiber is $140 \mathrm{~mm}$, and a 25 percent Vf composite has a maximum flexural strength of $74.27 \mathrm{MPa}$. The volume fraction of the fiber content in the composite is 30 percent; the increasing trend abruptly declines to $48.54 \mathrm{MPa}$. For a 25 percent Vf material, the maximum flexural strength is determined by the length of the fibers used in the composite; in this study, 110 and $140 \mathrm{~mm}$ were the fiber lengths used in the material. Additionally, flexural strength is influenced by the fiber content and length of the fiber. Extensive testing has revealed that 
perhaps the lengthy fiber carries the greatest flexural load compared to the short fiber.

In Figure 4, you can see the range of flexural modulus values for different AAM fiber volume concentrations. Once again, the flexural modulus significantly increases as the volume concentration rises. Although this shows an increase to $25 \%$ overall, this results in a $14.78 \mathrm{GPa}$ flexural modulus when the fiber length is $140 \mathrm{~mm}$. It is readily apparent that a fluctuation in the flexural modulus occurs when the fiber content of the substantive changes. When the volume of fiber content in the composites is 30 , one of the mechanical properties of the composites such as flexural strength reduced up to $5.72 \mathrm{GPa}$. Based on Figure 4, there are different stress and strain curves for different fiber weight fractions when using a tensile test at $20 \mathrm{~mm}$ length. This finding concludes that the optimum flexural modulus of the composite is acquired when the fiber length is $140 \mathrm{~mm}$ and the percentage of $\mathrm{Vf}$ is 25 percent. From validating all of the results (Figures 3 and 4), it is apparent that isophthalic polyester resin reinforced composite with the addition of 25 wt.\% chopped AAM fiber improved several mechanical properties such as flexural strength and modulus, tensile strength, and modulus. For the application of loads at volume fractions of $25 \%$ or greater, the fiber-reinforced effect is a challenging phenomenon for improving strength and modulus. At volume concentrations between 25\% and $75 \%$, the crack formation initiation is high. Expanding fiber volume fraction leads to an increase in the flexural and tensile modulus values.

To understand how sliced fiber-reinforced strength is determined by multiple factors, we examine how various factors (e.g., fiber strength, modulus, fiber length, the volume of fiber, fiber content, fiber content, and fiber positioning) enhance the mechanical properties of the sliced fiber-reinforced composite. In addition to such elements, the preparedness of the composite should indeed be considered. When in the matrix resin, sliced fibers have relatively high portions that are aligned in greater alignment. The presence of fibers-direct load transfer is observed, which results in an enhancement in the mechanical characteristics of the composite.

Natural fibers can be wider or narrower depending on the length of the fibers. Therefore, making an attempt to directly compare the composite properties of a composite object would be a difficult endeavor. At equal volume ratio and reinforcement type, this is among the easiest ways to prepare composite material. It is one of the straightforward approaches that have significant value in teaching comprehension.

3.4. Effect of Moisture Absorption Characteristics. The effects of fiber content on the composite specimen's moisture absorption behavior are shown in Figures 5-7. The absorption of moisture increased in all cases with increased fiber content. This is explained by improving the formation of microbial in the resin matrix [28]. Figure 5 illustrates the outcome of fiber concentration on the first day and then the fifth day of humidity absorption of composite fiber of

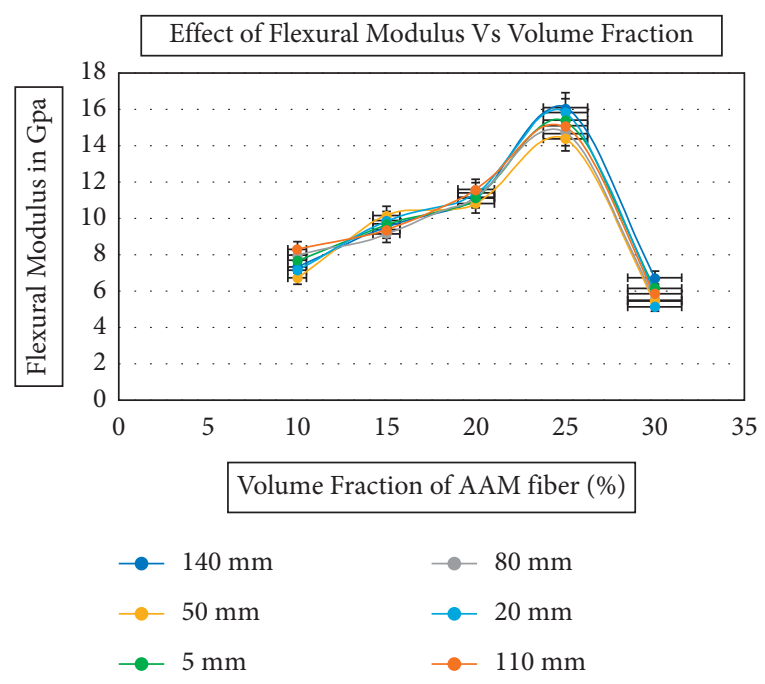

Figure 4: The relationship between the flexural modulus and the volume fraction of AAM fibers with varying fiber lengths.

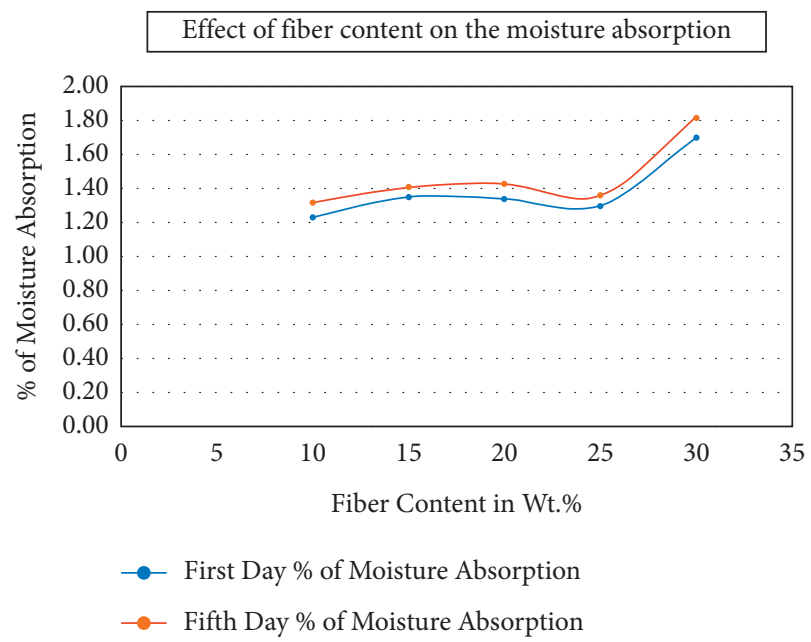

FIGURE 5: Moisture absorption of $20 \mathrm{~mm}$ fiber composites with different fiber volumes.

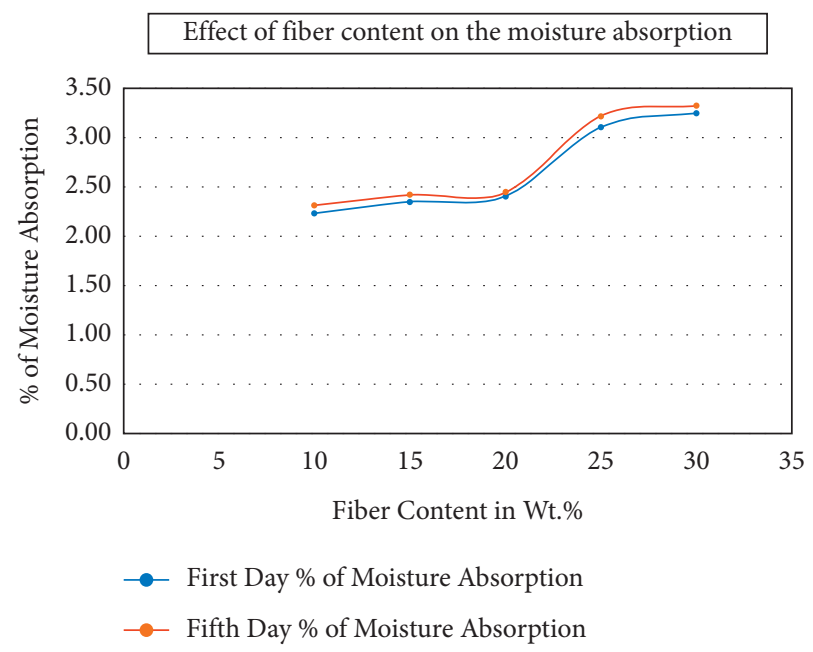

FIgURE 6: Water absorption of $140 \mathrm{~mm}$ length of fiber composite with varying fiber concentrations. 


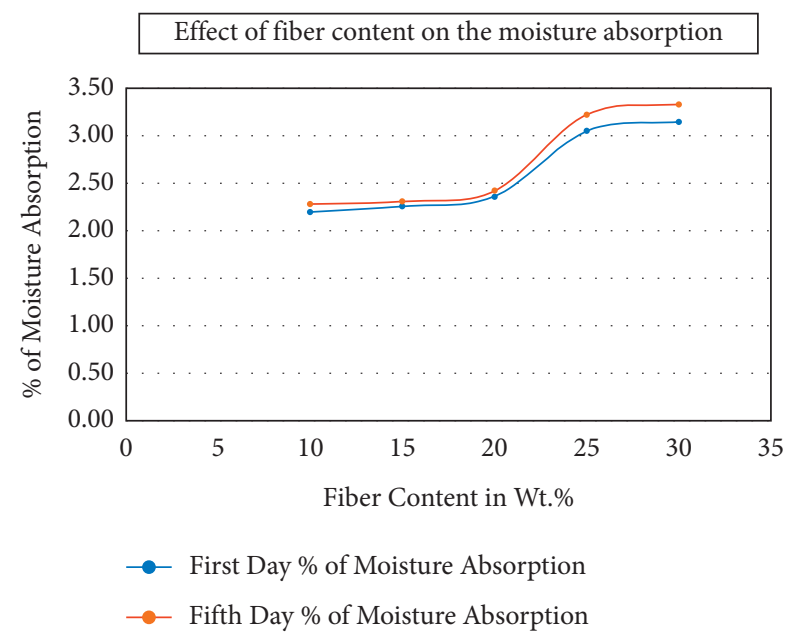

FIgURE 7: Water absorption of $100 \mathrm{~mm}$ length of fiber composite with varying fiber concentrations.

$20 \mathrm{~mm}$. The moisture absorption frequency was identified for the first and fifth days. 10wt.\% of the composite observed moisture content up to $75 \%$. Similarly, 20wt.\% observed up to $85 \%$, 30wt. $\%$ observed up to $85 \%$, and $35 w t . \%$ observed up to $89 \%$. Figure 7 showcases the analysis of the fiber content on water intake of the $100 \mathrm{~mm}$ length of fiber-reinforced composites during the above-stated days.

The water absorption assortment increased almost all the weight percentages of the composites during the first and fifth days of testing. The result produced for $10 \mathrm{wt} . \%$ of the composite was absorbed up to $34.3 \%$, 20wt.\% moisture intake percentage was $39.89 \%$, and $30 \mathrm{wt} . \%$ of the composite was absorbed up to 43.82 . Figure 6 shows the effect of fiber content at the end of the first and fifth days on moisture content of composite fibers of $140 \mathrm{~mm}$. At 10wt percent for the first day and for the fifth day, 20wt percent and 30wt percent of fiber composites stood at $27.6 \%, 32.1 \%$, and $41.1 \%$. When the content of fibers increased, the absorption of humidity increased. The third, fourth, and fifth days of humidity absorption were almost identical: 10 wt.\% and $100 \mathrm{~mm}$ and $20 \mathrm{wt} . \%$ and $100 \mathrm{~mm}$. The components were also found in $10 \mathrm{wt} . \%$ and $140 \mathrm{~mm}$ and $30 \mathrm{wt} . \%$ and $140 \mathrm{~mm}$. These components were found. The $150 \mathrm{~mm}$ length of the composite absorbed more moisture content when compared to other lengths of the AAM fibers, such as $50 \mathrm{~mm}$ and $100 \mathrm{~mm}$. One of the most important findings from these studies is that increasing the amount of fiber and the length of the fiber will increase moisture absorption.

\subsection{Tensile Strength Is Influenced by Moisture Absorption.} The mechanical properties of the AAM fiber-reinforced polyester composites will affect the various consequence such as interphase of the region, interfaces of the fiber/ matrix, fiber content or quantity, and directions of the fiber kept in the composite in the reinforcement. The varying fiber quantity and length in the AAM fiber-reinforced composite examined in both the dry and wet conditions are shown in Figure 8. In dry conditions, the tensile strengths of the

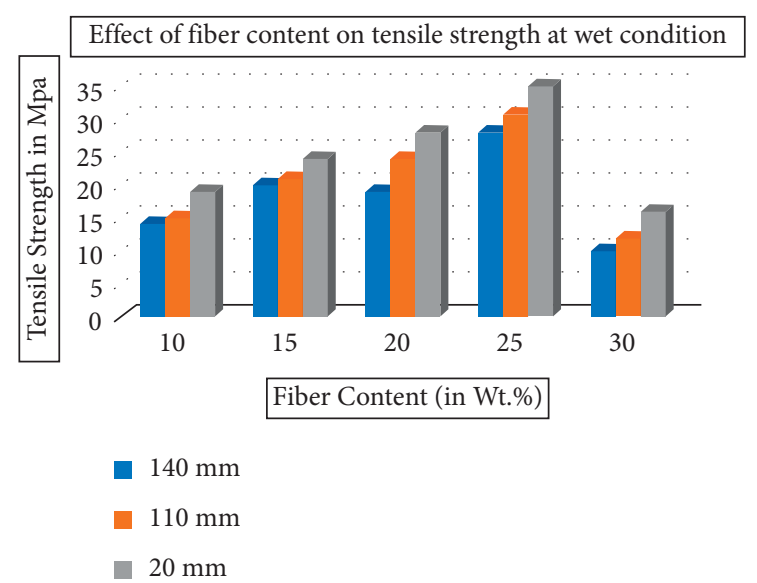

FIGURE 8: Tensile behavior of dry and wet conditions of composites with respect to the fiber content.

composites with 10 weight percent and $20 \mathrm{~mm}, 20$ weight percent and $20 \mathrm{~mm}$, and 30 weight percent and $20 \mathrm{~mm}$ were 31.5 $\mathrm{MPa}, 40.2 \mathrm{MPa}$, and 47.4 $\mathrm{MPa}$, respectively, in both directions. From ten percent to thirty percent, there is a 49.6 the maximum. At dry conditions, the $10 \mathrm{wt} . \%$ with $100 \mathrm{~mm}$ length of the fiber resulted in $39.7 \mathrm{Mpa}$ tensile strength. Similarly, 20 wt.\% with the same length of the composite tensile strength was $43.6 \mathrm{Mpa}$. The $30 \mathrm{wt} . \%$ of the composite with $100 \mathrm{~mm}$ length had a tensile strength of $51.5 \mathrm{Mpa}$. From ten percent to thirty percent, there was a $27.7 \%$ increment. At dry conditions, the tensile strength of $10 \mathrm{wt}$ percent and $140 \mathrm{~mm}$ length of composite is $47.1 \mathrm{Mpa}$, that of $20 \mathrm{wt}$ percent and $140 \mathrm{~mm}$ length of the composites is $49.9 \mathrm{Mpa}$, and that of $30 \mathrm{wt}$ percent and $140 \mathrm{~mm}$ composites was $57.7 \mathrm{Mpa}$. From ten percent to thirty percent, there was a 21.0 percent improvement. The higher fiber content and the exact length of the composite in dry conditions had provided increased tensile strength. However, as fiber length and content increased, the percentage of betterment decreased. At wet conditions, the 10wt.\% of $20 \mathrm{~mm}$ length composite tensile strength was 29.1 Mpa. Similarly, 30 wt.\% with $20 \mathrm{~mm}$ length of the composite tensile strength was $42.1 \mathrm{Mpa}$. When compared to plain samples, the reductions were 6.1 percent and 10.7 percent, respectively. In moisture conditions, the tensile strengths of $30 \mathrm{wt}$. $\%$ with $20 \mathrm{~mm}$ length fiber, $30 \mathrm{wt} . \%$ with $100 \mathrm{~mm}$ length fiber, and $30 \mathrm{wt} . \%$ with $140 \mathrm{~mm}$ length fiber composites samples were tested decreased by 10.7 percent, 14.8 percent, and 22.5 percent, respectively. In wet conditions, the enhancement of the tensile modulus and strength of the tested composite sample continued to increase because the fiber content and length continued to increase. However, in moisture consumed samples, the variation of increment in mechanical properties of all lengths of fibers with different wt.\% was less. This could be because the soaking of composites samples in moisture affected the bonding of the fiber-matrix reinforcement, causing the delamination and reduction in the mechanical behavior of the composite materials. In general, it was anticipated that when higher fiber wt.\% composites were submerged in water, the tensile behavior composites were 
decreased when compared with the dry samples. It is worth noting that the wet tensile strength of $20 \mathrm{wt} . \%$ and $20 \mathrm{~mm}$ composites samples was almost identical to that of $10 \mathrm{wt} . \%$ and $100 \mathrm{~mm}$ composites samples (36.3 MPa and $35.7 \mathrm{MPa}$ ). The fiber content was higher in 20 wt percent and $20 \mathrm{~mm}$ composites samples than in $10 \mathrm{wt}$ percent and $100 \mathrm{~mm}$ composites samples, and fiber length was shorter in twenty weight percentage and length of $20 \mathrm{~mm}$ specimen composites than in $10 \mathrm{wt}$ percent and $100 \mathrm{~mm}$ composites samples. The tensile behavior for the 20 weights $\%$ with $100 \mathrm{~mm}$ fiber length was $44.6 \mathrm{Mpa}$. The dry sample composite tensile strength of 30 weight $\%$ with $150 \mathrm{~mm}$ length fiber was $44.9 \mathrm{Mpa}$.

This became directly related to the amount of moisture absorbed in 30 weights\% with $140 \mathrm{~mm}$ length of composites samples. The cellulose fibers swelled when the fiber content interface was exposed to moisture from the atmosphere. As a result of this, shear stress developed at the interface, resulting in fiber delamination, interlaminar, and structural rigidity loss, as shown in Figure 8. Immersion in water thus had an effect on composite strength.

3.6. Impact on Flexural Strength due to Moisture Absorption. The flexural properties seem to be another prominent and frequently analyzed property due to their various applications in composite materials. The flexural properties of AAM polyester composites containing 10-30 weight\% fiber content at different fiber lengths are shown in Figure 9. At dry conditions, due to the increased content of fiber and its length, the flexural strength increased. In dry condition, the 10 wt.\% with $20 \mathrm{~mm}$ length of fiber flexural strength was $50.3 \mathrm{Mpa}$. Similarly, $30 \mathrm{wt} . \%$ with $20 \mathrm{~mm}$ fiber length was 63.1 Mpa. The increased percentage difference is $23.91 \mathrm{Mpa}$ when compared to both samples. In dry conditions, the tensile strength of $10 \mathrm{wt} . \%$ and $100 \mathrm{~mm}$ length of composite sample increased by $22.5 \%$ and $10.2 \%$ correspondingly, for $10 \mathrm{wt} . \%$ with $100 \mathrm{~mm}$ length of fiber to $30 \mathrm{wt} . \%$ with $100 \mathrm{~mm}$ length of composites. In dry conditions, the highest flexural strength achieved $30 \mathrm{wt} . \%$ with $100 \mathrm{~mm}$ fiber length of the composites. At the wet conditions test, the flexural properties of the composites with $10 \mathrm{wt} . \%, 20 \mathrm{wt} . \%$, and $30 \mathrm{wt} . \%$ with the length of $20 \mathrm{~mm}$ had the tensile strength of 47.4 Mpa, 50.1 Mpa, and 55.6 Mpa. When compared to the dry samples, the reduction in percentages was $4.7,7.6$, and $9.3 \%$. At we condition, the flexural behavior of composites of $10 \mathrm{wt} . \%, 20 \mathrm{wt} . \%$, and $30 \mathrm{wt} . \%$ with $100 \mathrm{~mm}$ length of fiber had the following flexural properties $51.8 \mathrm{Mpa}, 52.5 \mathrm{Mpa}$, and $61.5 \mathrm{Mpa}$. The percentage reductions were compared with dry samples that were $7.9 \%, 11.4 \%$, and $11.8 \%$, respectively. The 10 weight $\%$ with $140 \mathrm{~mm}$ length of the fiber, $20 \mathrm{wt} . \%$ with $140 \mathrm{~mm}$ fiber length, and $30 \mathrm{wt} . \% 140 \mathrm{~mm}$ fiber length flexural strength were $52.7 \mathrm{Mpa}, 54.4 \mathrm{Mpa}$, and 60.9 Mpa. When compared to dry samples, the reduction percentages were $11.4 \%, 17.5 \%$, and 20.7 Percent.

At wet conditions, due to the increased length and quantity of the fiber, the flexural behavior of the composites was increased. However, as higher quantity in the composites and increased length of fiber present in the composite

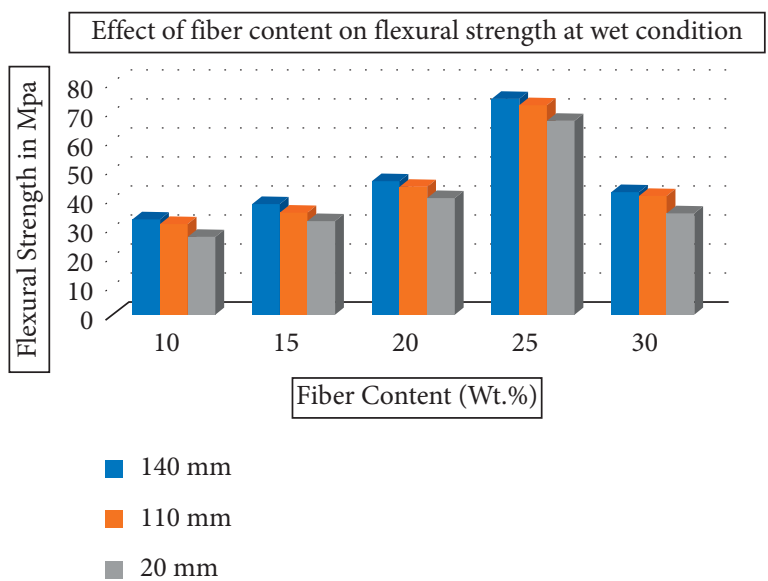

FIGURE 9: Flexural behavior in dry and wet conditions with varying fiber content.

were reduced, the strength properties increased in the samples [32].

The 10-30 wt.\% fiber content with various lengths of the test samples of dry and wet state composites showed a huge expansion in flexural strength. Under dry conditions, the 30 wt.\% with $20 \mathrm{~mm}$ fiber length composites had increased flexural behavior when compared with $20 \mathrm{wt} . \%$ with $10 \mathrm{~mm}$ fiber length of composites. There were two cases of fiber: one was increased fiber content with the length of fiber being less and another case [33] was the fiber content and length of the fiber also being high. It was noted that the $30 \mathrm{wt} . \%$ with $100 \mathrm{~mm}$ length of the composites was higher strength when compared with increased length of fiber present in the composites such as 30wt.\% and $140 \mathrm{~mm}$ fiber length.

The composite reinforcement was dragged to rupture due to the deflection during the bending of the sample test shown in the figure. Due to the low fiber content, the fiber pull-out from the matrix was observed. It was identified that the debonding, delamination, fiber breakage, and matrix failure occurred during the bend testing (Figure 9). Due to expanded moisture content in the composites, the flexural properties decreased incrementally in wet conditions, and the length of fiber content and volume also increased. The poor fiber-matrix interfacial bonding causes a diminished flexural behavior after the absorption of the moisture. The development of the hydrogen bond in the cellulose of fiber and in water molecules resulted in diminished mechanical behavior due to high moisture absorption. The natural fiber observed only the less amount of moisture content when it presents in the more $\mathrm{OH}$ group $\%$. The huge accumulation of the moisture in the composites was caused by dimensional variations in the composites, lack of interfacial bonding, and strength between the fiber matrix. Because of the above issues, the mechanical properties were gradually reduced [34]. It was identified that the flexural behavior was equal in many of the weight percentages of the composites with varying lengths. The proportion ratio, humidity, and manufacturing methods of the composites influenced the moisture behavioral characteristics. The volume fraction and all other techniques decided the porosity of the composite. 
The importance of the fiber-matrix adhesion on flexural strength was further highlighted in the figure (Figure 9).

\section{Conclusions}

(i) The new AAM fiber has improved mechanical properties and accessibility over other conventional materials. These conclusions have been reached based on a considerable amount of experimental testing.

(ii) AAM fibers have a higher tensile strength and modulus of elasticity than other natural fibers. In comparison to other fibers, the AAM fiber has a very low density.

(iii) With different fiber volume fractions and fiber lengths, the flexural and tensile behavior of Agave Angustifolia Marginata isophthalic (polyester) composite is significantly improved. Improved fiber content resulted in an increase in the tensile behavior of the composites. The chopped fiber isophthalic polyester reinforcement reaches its improved tensile strength and modulus at a $25 \% \mathrm{Vf}$ about the $20 \mathrm{~mm}$ length of the fiber. Overall, decreased fiber lengths have greater strength and a greater number of fiber ends, which accumulate in the composite.

(iv) To achieve the increased flexural characteristics and modulus of the carved fiber isophthalic polyester composite, which reached $25 \% \mathrm{Vf}$ for $110 \mathrm{~mm}$ and $140 \mathrm{~mm}$ fiber lengths, the maximum flexural strength and modulus of the sliced fiber isophthalic polyester composite are obtained at $25 \%$ Vf. However, the values have been significantly improved by an increase of $140 \mathrm{~mm}$.

(v) The impact of moisture absorption behavior on the mechanical characteristics of AAM fiber-reinforced hybrid polyester composites was explored in this research, and the outcomes have been linked to composites containing dried fibers.

(vi) Flexural and tensile strength increased as fiber content and length increased in dry conditions. Tensile and flexural strength are greatly reduced when the material is wet. At both dry and wet conditions, the impact strength decreased as the fiber content and length increased.

(vii) The degradation of the fiber-matrix interface caused by moisture exposure resulted in a significant drop in mechanical properties.

(viii) To achieve the positive hybrid effect and develop an optimized material system, it is necessary to understand the moisture absorption characteristics of natural fiber-reinforced hybrid composite materials.

\section{Data Availability}

The data used to support the findings of this study are included within the article.

\section{Disclosure}

The publication is only for the academic purpose of Addis Ababa Science and Technology University, Ethiopia.

\section{Conflicts of Interest}

The authors declare that there are no conflicts of interest regarding the publication of this paper.

\section{References}

[1] B. J. Manujesh, M. R. Prajna, M. P. Sham Aan, C. V. Majida, and P. J. Antony, "Flexural characterization of foam cored E-glass reinforced smart materials using artificial neural network," Materials Today Proceedings, vol. 5, no. 10, pp. 21305-21313, 2018.

[2] L. Prasad, G. Singh, and M. Pokhriyal, "A comparative study on physical and mechanical behaviour of functionally graded composite materials reinforced with natural fillers," Materials Today Proceedings, vol. 5, no. 9, Article ID 16990, 2018.

[3] V. Chaudhary and F. Ahmad, "A review on plant fiber reinforced thermoset polymers for structural and frictional composites," Polymer Testing, vol. 91, Article ID 106792, 2020.

[4] K. Viswanath Allamraju, "Study of mechanical behaviour of hybrid jute nano fiber composite," Materials Today Proceedings, vol. 5, no. 9, Article ID 20750, 2018.

[5] S. J. Sbai, A. Boukhriss, S. Majid, and S. Gmouh, "Chapter 20 the Recent Advances in Nanotechnologies for Textile Functionalization," in Advances in Functional and Protective Textiles, S. ul-Islam and B. S. Butola, Eds., Woodhead Publishing, Sawston, Cambridge, pp. 531-568, 2020.

[6] M. Mazumder, R. Ahmed, A. Wajahat Ali, and S.-J. Lee, "SEM and ESEM techniques used for analysis of asphalt binder and mixture: a state of the art review," Construction and Building Materials, vol. 186, pp. 313-329, 2018.

[7] S. S. Todkar and S. A. Patil, "Review on mechanical properties evaluation of pineapple leaf fibre (PALF) reinforced polymer composites," Composites Part B: Engineering, vol. 174, Article ID 106927, 2019.

[8] G. Saravanan, G. B. Bhaskar, E. Kaviyarasan, B. Naveen, S. Prabakaran, and S. Rajesh, "Experimental investigation of mechanical behavior of Bauhinia racemosa - based glass fiber reinforced composite," Materials Today Proceedings, vol. 16, pp. 758-765, 2019.

[9] Y. H. Mugahed Amran, R. Alyousef, R. S. M. Rashid, H. Alabduljabbar, and C.-C. Hung, "Properties and applications of FRP in strengthening RC structures: a review," Structures, vol. 16, pp. 208-238, 2018.

[10] C. Sowmya, V. Ramesh, and D. Karibasavaraja, "An experimental investigation of new hybrid composite material using hemp and jute fibres and its mechanical properties through finite element method," Materials Today Proceedings, vol. 5, no. 5, pp. 13309-13320, 2018.

[11] B. Han, W.-W. Hui, Q.-C. Zhang et al., "A refined quasi-3D zigzag beam theory for free vibration and stability analysis of multilayered composite beams subjected to thermomechanical loading," Composite Structures, vol. 204, pp. 620-633, 2018.

[12] R. Parhi, "16 - Nanocomposite for Transdermal Drug Delivery," in Applications of Nanocomposite Materials in Drug Delivery, Inamuddin, A. M. Asiri, and A. Mohammad, Eds., Woodhead Publishing, Sawston, Cambridge, pp. 353-389, 2018. 
[13] K. Deepak, N. S. Reddy, and T. V. S. Naidu, "Thermosetting polymer and nano clay based natural fiber bio- composites," Procedia Materials Science, vol. 10, pp. 626-631, 2015.

[14] B. N. Raju, K. Ramji, and V. S. R. K. Prasad, "Mechanical properties of glass fiber reinforced polyester $\mathrm{ZnO}$ NanoComposites," Materials Today Proceedings, vol. 2, no. 4, pp. 2817-2825, 2015.

[15] N. Dubey and G. Agnihotri, "Flexural and impact properties of midrib of coconut palm leaves reinforced polyester," Materials Today Proceedings, vol. 4, no. 2, pp. 3422-3430, 2017.

[16] A. Gnanavelbabu, P. Saravanan, K. Rajkumar, P. Sabarinathan, and S. Karthikeyan, "Mechanical strengthening effect by various forms and orientation of glass fibre reinforced isopthalic polyester polymer composite," Materials Today Proceedings, vol. 5, no. 13, Article ID 26850, 2018.

[17] V. Puri, P. Chakrabortty, S. Anand, and S. Majumdar, "Bamboo reinforced prefabricated wall panels for low cost housing," Journal of Building Engineering, vol. 9, pp. 52-59, 2017.

[18] N. Belayachi, D. Hoxha, and B. Ismail, "Impact of fiber treatment on the fire reaction and thermal degradation of building insulation straw composite," Energy Procedia, vol. 139, pp. 544-549, 2017.

[19] K. Sudha Madhuri, H. Raghavender Rao, and B. Chandramohan Reddy, "Experimental investigation on the mechanical properties of Hardwickia Binata fibre reinforced polymer composites," Materials Today Proceedings, vol. 5, no. 9, Article ID 19899, 2018.

[20] M. A. Fuqua, S. Huo, and C. A. Ulven, "Natural fiber reinforced composites," Polymer Reviews, vol. 52, no. 3, pp. 259-320, 2012.

[21] O. Faruk, A. K. Bledzki, H.-P. Fink, and M. Sain, "Progress report on natural fiber reinforced composites," Macromolecular Materials and Engineering, vol. 299, no. 1, pp. 9-26, 2014.

[22] S. V. Joshi, L. T. Drzal, A. K. Mohanty, and S. Arora, "Are natural fiber composites environmentally superior to glass fiber reinforced composites?" Composites Part A: Applied Science and Manufacturing, vol. 35, no. 3, pp. 371-376, 2004.

[23] X. Li, L. G. Tabil, and S. Panigrahi, "Chemical treatments of natural fiber for use in natural fiber-reinforced composites: a review," Journal of Polymers and the Environment, vol. 15, no. 1, pp. 25-33, 2007.

[24] V. Mohanavel, T. Sathish, M. Ravichandran, K. Arul, and R. Subbiah, "Mechanical properties of waste silk fibre reinforced PLA bio composites manufactured through hand layup method," Journal of Physics: Conference Series, vol. 2027, no. 1, Article ID 012016, 2021

[25] K. Rajkumar, N. Vinoth, R. Santhosh Kumar et al., "Mechanical and water absorption behaviour of palm seed particles based hybrid bio-composites," Journal of Physics: Conference Series, vol. 2027, no. 1, Article ID 012006, 2021.

[26] P. J. Herrera-Franco and A. Valadez-González, "A study of the mechanical properties of short natural-fiber reinforced composites," Composites Part B: Engineering, vol. 36, no. 8, pp. 597-608, 2005.

[27] M. J. John and R. D. Anandjiwala, "Recent developments in chemical modification and characterization of natural fiberreinforced composites," Polymer Composites, vol. 29, no. 2, pp. 187-207, 2008.

[28] V. Mohanavel, T. Sathish, M. Ravichandran, P. Ganeshan, M. M. Ravi Kumar, and R. Subbiah, "Experimental investigations on mechanical properties of cotton/hemp fiber reinforced epoxy resin hybrid composites," Journal of Physics: Conference Series, vol. 2027, no. 1, Article ID 012015, 2021.

[29] R. Subbiah, B. K. Kumar, T. Sathish et al., "Wear properties of waste silk fibre reinforced PLA bio composites using taguchi technique," Journal of Physics: Conference Series, vol. 2027, no. 1, Article ID 012012, 2021.

[30] A. Valadez-Gonzalez, J. M. Cervantes-Uc, R. Olayo, and P. J. Herrera-Franco, "Effect of fiber surface treatment on the fiber-matrix bond strength of natural fiber reinforced composites," Composites Part B: Engineering, vol. 30, no. 3, pp. 309-320, 1999.

[31] L. Kerni, S. Singh, A. Patnaik, and N. Kumar, "A review on natural fiber reinforced composites," Materials Today Proceedings, vol. 28, pp. 1616-1621, 2020.

[32] B. Biswas, N. R. Bandyopadhyay, and A. Sinha, "Mechanical and dynamic mechanical properties of unsaturated polyester resin-based composites," in Unsaturated Polyester Resins, pp. 407-434, Elsevier, Chennai, Tamilnadu, 2019.

[33] V. Mohanavel, T. Raja, A. Yadav, M. Ravichandran, and J. Winczek, "Evaluation of mechanical and thermal properties of jute and ramie reinforced epoxy-based hybrid composites," Journal of Natural Fibers, vol. 1, pp. 1-11, 2021.

[34] C. A. Chairman, M. Ravichandran, V. Mohanavel et al., "Mechanical and abrasive wear performance of titanium dioxide filled woven glass fibre reinforced polymer composites by using taguchi and EDAS approach," Materials, vol. 14, no. 18, Article ID 5257, 2021.

[35] R. R Niranjan, S. J Kokan, R. S Narayanan, and R Sridhar, "Fabrication and testing of abaca fibre reinforced epoxy composites for automotive applications," Advanced Materials Research, Trans Tech Publications Ltd, vol. 718, 2013.

[36] G. Kalusuraman, I Siva, J. T. W Jappes, G Xiao-Zhi, and S. C Amico, "Fibre loading effects on dynamic mechanical properties of compression moulded luffa fibre polyester composites," International Journal of Computer Aided Engineering and Technology, vol. 10, pp. 157-165, 2018.

[37] K. N. Keya, fnm au, N. A. Kona et al., "Natural fiber reinforced polymer composites: history, types, advantages, and applications," Materials Engineering Research, vol. 1, no. 2, pp. 69-87, 2019.

[38] F. Sarasini and V. Fiore, "A systematic literature review on less common natural fibres and their biocomposites," Journal of Cleaner Production, vol. 195, pp. 240-267, 2018.

[39] A. V. Oskouei, M. Bazli, H. Ashrafi, and M. Imani, "Flexural and web crippling properties of GFRP pultruded profiles subjected to wetting and drying cycles in different sea water conditions," Polymer Testing, vol. 69, pp. 417-430, 2018.

[40] A. Dhanola, A. S. Bisht, A. Kumar, and A. Kumar, "Influence of natural fillers on physico-mechanical properties of luffa cylindrica/polyester composites," Materials Today Proceedings, vol. 5, no. 9, pp. 17021-17029, 2018.

[41] T. Ramakrishnan, R. S. Kumar, S. Balasubramani, R. Jeyakumar, S. J. S. Chelladurai, and R. Ramamoorthi, "Experimental investigation of the effect of various chemical treatments on Agave angustifolia Marginata fibre," in Green Materials and Advanced Manufacturing Technology, pp. 173-190, CRC Press, FA, USA, 2020.

[42] R. S. Kumar, T. Ramakrishnan, and S. Balasubramani, "Multiobjective optimization of BSL 165 aluminium composite for aeronautical applications," in Green Materials and Advanced Manufacturing Technology, pp. 217-236, CRC Press, FA, USA, 2020.

[43] S. Balasubramani, N. Balaji, T. Ramakrishnan, R. Sureshkumar, S. J. S. Chelladurai, and S. J. S Chelladurai, 
"Defect identification in casting surface using image processing techniques," in Green Materials and Advanced Manufacturing Technology, pp. 191-198, CRC Press, FA, USA, 2020.

[44] S. Ganeshkumar, V. Thirunavukkarasu, R. Sureshkumar, S. Venkatesh, and T. Ramakrishnan, "Investigation of wear behaviour of silicon carbide tool inserts and titanium nitride coated tool inserts in machining of EN8 steel," International Journal of Mechanical Engineering \& Technology, vol. 10, no. 1, pp. 1862-1873, 2019.

[45] T. Ramakrishnan and S. Pavayee Subramani, "Investigation of physico-mechanical and moisture absorption characteristics of raw and alkali treated new Agave angustifolia Marginata (AAM) fiber," Materials Science, vol. 24, no. 1, pp. 53-58, 2018.

[46] T. Ramakrishnan and P. S. Sampath, "Dry sliding wear characteristics of new short Agave angustifolia Marginata (AAM) fiber-reinforced polymer matrix composite material," Journal of Biobased Materials and Bioenergy, vol. 11, no. 5, pp. 391-399, 2017.

[47] R. Jeyakumar, P. S. Sampath, R. Ramamoorthi, and T. Ramakrishnan, "Structural, morphological and mechanical behaviour of glass fibre reinforced epoxy nanoclay composites," International Journal of Advanced Manufacturing Technology, vol. 93, no. 1-4, pp. 527-535, 2017.

[48] T. Ramakrishnan and P. S. Sampath, "Experimental investigation of mechanical properties of untreated new Agave Angustifolia Marginata fiber reinforced epoxy polymer matrix composite material," Journal of Advances in Chemistry, vol. 13, no. 4, pp. 6120-6126, 2017.

[49] R. Ramamoorthi, R. Jeyakumar, and T. Ramakrishnan, "Effect of nanoparticles on the improvement of mechanical properties of epoxy based fiber - reinforced composites - a review," International Journal for Science and Advance Research in Technology, vol. 3, no. 11, pp. 1251-1256, 2017.

[50] T. Ramakrishnan, P. S. Sampath, and R. Ramamoorthi, "Investigation of mechanical properties and morphological study of the alkali treated Agave angustifolia Marginata fiber reinforced epoxy polymer composites," Asian Journal of Research in Social Sciences and Humanities, vol. 6, no. 9, pp. 461-472, 2016.

[51] T. Ramakrishnan and P. S. Sampath, "Thermogravimetric analysis (TGA) and the effect of moisture absorption on the mechanical properties of new Agave angustifolia Marginata fiber (AAMF) reinforced epoxy polymer composite material," International Journal of Printing, Packaging \& Allied Sciences, vol. 4, no. 5, pp. 3245-3256, 2016.

[52] T. Ramakrishnan, K. Sathish, P. S. Sampath, and S. Anandkumar, "Experimental investigation and optimization of surface roughness of AISI 52100 alloy steel material by using Taguchi method," Advances in Natural and Applied Sciences, vol. 10, no. 6, pp. 130-138, 2016.

[53] S. Gnanasekaran, S. J. S Chelladurai, T Ramakrishnan et al., "Optimizing the characteristics of the laser hardfacing process parameters to maximize the wear resistance of Ni-based hardfaced deposits using the RSM technique," Advances in $\mathrm{Ma}$ terials Science and Engineering, vol. 2021, Article ID 3665631, 15 pages, 2021. 